\title{
Probabilistic and sensitivity analysis of Botlek Bridge structures
}

\author{
Juraj $\mathrm{Králik}^{1,{ }^{*}}$ and Peter Rosko ${ }^{2}$ \\ ${ }^{1}$ STU Bratislava, Faculty of Civil Engineering, Radlinského 11, 81368 Bratislava, Slovakia \\ ${ }^{2}$ Institute for Building Construction and Technology Centre of Mechanics and Structures, TU Vienna, \\ Austria
}

\begin{abstract}
This paper deals with the probabilistic and sensitivity analysis of the largest movable lift bridge of the world. The bridge system consists of six reinforced concrete pylons and two steel decks 4000 tons weight each connected through ropes with counterweights. The paper focuses the probabilistic and sensitivity analysis as the base of dynamic study in design process of the bridge. The results had a high importance for practical application and design of the bridge. The model and resistance uncertainties were taken into account in LHS simulation method.
\end{abstract}

\section{Introduction}

During the structural design process, an engineer has to consider problems of the safety, reliability and durability of a single structural element as well as the entire structure from the point of view of its planned life cycle. Randomness in the loading and the environmental effects, the variability of the material and geometric characteristics of structures and many other "uncertainties" affecting errors in the computing model lead to a situation where the actual behavior of a structure is different from the modeled one [1 - 9]. Recent advances and the general accessibility of information technologies and computing techniques give rise to assumptions concerning the wider use of the probabilistic assessment of the reliability of structures through the use of simulation methods [5].

\section{Simulation Methods}

In the case of simulation methods the failure probability is calculated from the evaluation of the statistical parameters and theoretical model of the probability distribution of the reliability function $Z=g(\boldsymbol{X})$. The failure probability is defined as the best estimation on the base of numerical simulations in the form

$$
p_{f}=\frac{1}{N} \sum_{i=1}^{N} I\left[g\left(X_{i}\right) \leq 0\right] \leq p_{d}
$$

\footnotetext{
* Corresponding author: juraj.kralik@stuba.sk
} 
where $N$ in the number of simulations, $g($.$) is the failure function, I[$.$] is the function with$ value 1 if the condition in the square bracket is fulfilled, otherwise is equal to 0 .

Variation of the failure function can be defined by Melchers [10] in the form

$$
s_{p_{f}}^{2}=\frac{1}{(N-1)}\left\{\frac{1}{N}\left[\sum_{i=1}^{N} I^{2}\left[g\left(X_{i}\right) \leq 0\right]\right]-\left[\frac{1}{N} \sum_{i=1}^{N} I\left[g\left(X_{i}\right) \leq 0\right]\right]^{2}\right\}
$$

The various forms of analyses (statistical analysis, sensitivity analysis, probabilistic analysis) can be performed. Most of these methods are based on the integration of Monte Carlo $(M C)$ simulations. Three categories of methods have been presently realized - Direct methods, approximation methods or modified methods.

The most effective method is the modified $L H S$ method based on the same number of simulations of the safety function as in the $M C$ method [5]. Using the $L H S$ strategy, we get values like the reliability reserve parameter - the mean value of safety function.

The modified LHS method is based on the simulations of the function $g(\boldsymbol{X})$ so thus $M C$ method, but the definition domain of the distribution function $\Phi(X)$ is divided to $N$ intervals with the identical probability $1 / N$. Characteristic values of the simulations as calculated randomly on the base of $K$ permutation integer number $1,2, \ldots N$. The reliability function $g(\boldsymbol{X})$ must be determined from the $N$ simulation. The interval of the random simple is used one time only.

This method gives us the best estimation of the statistical parameters of the structure in the comparison with $M C$ method.

\section{Botlek Bridge structure}

The new Botlek Bridge recently built in Rotterdam (Holland) with two lifting spans of approximately $100 \mathrm{~m}$ and pylons reaching over $60 \mathrm{~m}$ above water level is the largest vertical - lift bridge in the world.

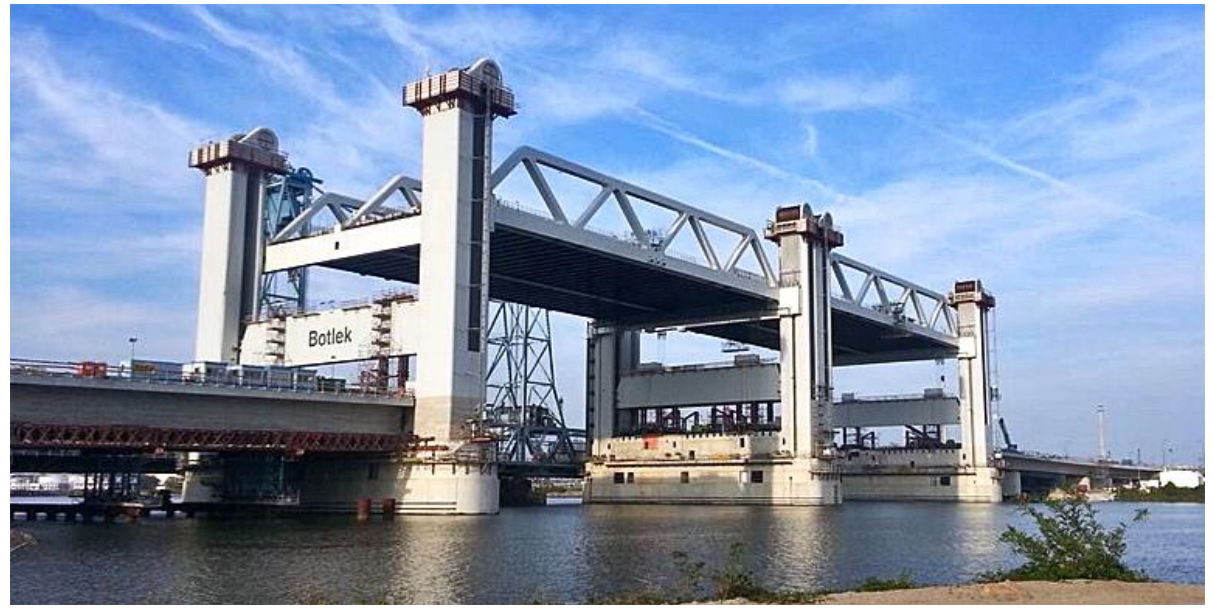

Fig. 1. Botlek Bridge.

The value of this project was approximate equal to 1.5 billion EUR. The design analysis of sophisticated structures of high importance require more detailed and expensive analyses, provide an opportunity for theory development, comparison of different analysis procedures and gaining experiences [11]. Because of dynamic loading (traffic loads in "down position" of decks, movement of decks, wind loads and seismic loads), the movable 
bridge model for deterministic and consistently the stochastic analysis was developed. The paper focuses the probabilistic analysis as the base of dynamic study in design process of the bridge.

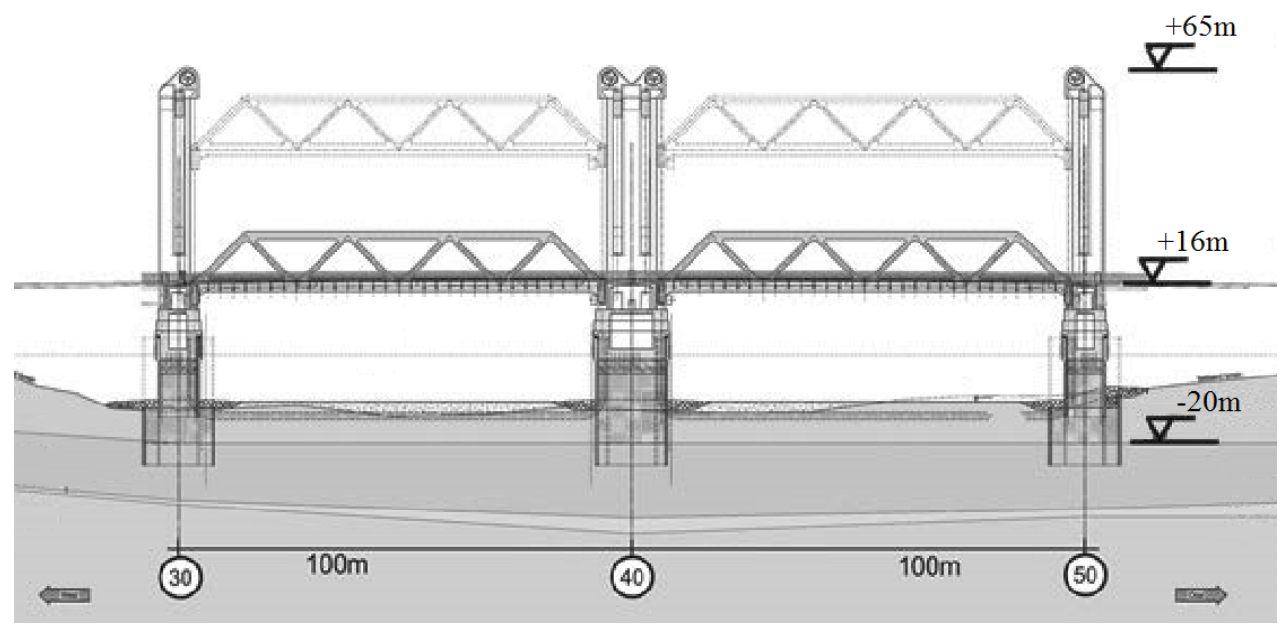

Fig. 2. Botlek Bridge. Section plan.

Two steel decks, 4000 tons weight each, are independently vertically movable on six concrete towers - the lifting height is $31 \mathrm{~m}$. The length of steel decks is $96 \mathrm{~m}$, the width 49 $\mathrm{m}$ (each deck has approximately the area of soccer stadium). The lifting system is fully balanced. The four concrete counterweights are guided on pylon towers and are connected through ropes with decks at their ends. The three main bridge piers (from left to right in Figure 1: Pier 30, Pier 40 and Pier 50) are founded on rigid concrete blocks with footing dimensions of $15 \times 60 \mathrm{~m}$, at $8 \mathrm{~m}$ below river bed at the top of the first dense (Pleistocene) sand layer. For the geotechnical design the foundation was essentially treated as a shallow foundation [12]. At a depth of approximately $16 \mathrm{~m}$ below the foundation footing a relatively soft clay layer is present with varying thicknesses between 0 and $4 \mathrm{~m}$. This stratum complicated the design, especially with respect to the settlement behavior which has a major impact on the performance of the total bridge and influences the different design disciplines (e.g. mechanical, electrical and structural). This article considers the probabilistic analysis with respect to the deformation behavior of the subsoil which was undertaken as part of the foundation design.

\section{Soil-structure interaction}

For the determination of the soil parameters an extensive soil investigation has been performed [12]. A relatively dense grid of Cone Penetration Tests (CPT's) with a mutual distance of about $15 \mathrm{~m}$ was executed to a depth of about 3 times the foundation width. In addition, a number of boreholes were drilled and undisturbed samples were taken at regular intervals for geotechnical laboratory tests by means of light percussion drilling in combination with thin-walled samplers. From the CPT's and borehole logs the soil stratigraphy is determined, see Table 1 . The foundation is modelled as an infinitely stiff foundation block, supported by linear elastic (stochastic) springs at a spacing of about $3 \mathrm{~m}$. Since the foundation consists of a massive concrete block with a thickness of about $20 \mathrm{~m}$ the assumption of a stiff foundation is considered reasonable. 
In the case of the dynamic loads the soil material characteristics depend on compression wave $(P$ - wave) and shear wave ( $S$ - wave) velocities in the soil

$$
v_{P}=\sqrt{\frac{E_{d}(1-v)}{(1+v)(1-2 v) \rho}} \cong \sqrt{\frac{E_{d}}{\rho}}, \quad v_{S}=\sqrt{\frac{E_{d}}{2(1+v) \rho}}=\sqrt{\frac{G_{d}}{\rho}},
$$

where $v_{p}$ is the compression wave velocity, $v_{s}$ is the shear wave velocity, $E_{d}$ is the dynamic Young modulus, $G_{d}$ is the dynamic shear modulus, $v$ is the Poissonov number, $\rho$ is the soil density. The typical ranges of $P$ - and $S$-wave velocities for different subsoil conditions were published in [13] (see Fig. 3).

Table 1. General soil stratigraphy [12].

\begin{tabular}{|c|c|c|}
\hline $\begin{array}{c}\text { Top of layer } \\
\text { [m NAP] }\end{array}$ & Soil description & Soil layer \\
\hline From -7 to -14 & SAND, clayey & cover layer \\
\hline From -14 to -20 & SAND, (medium) dense & 1st sand layer \\
\hline From -33 to -39 & CLAY, stiff & deep clay layer \\
\hline From -34 to -42 & SAND, (medium) dense & 2nd sand layer \\
\hline At -60 & Max. investigation depth & \\
\hline
\end{tabular}

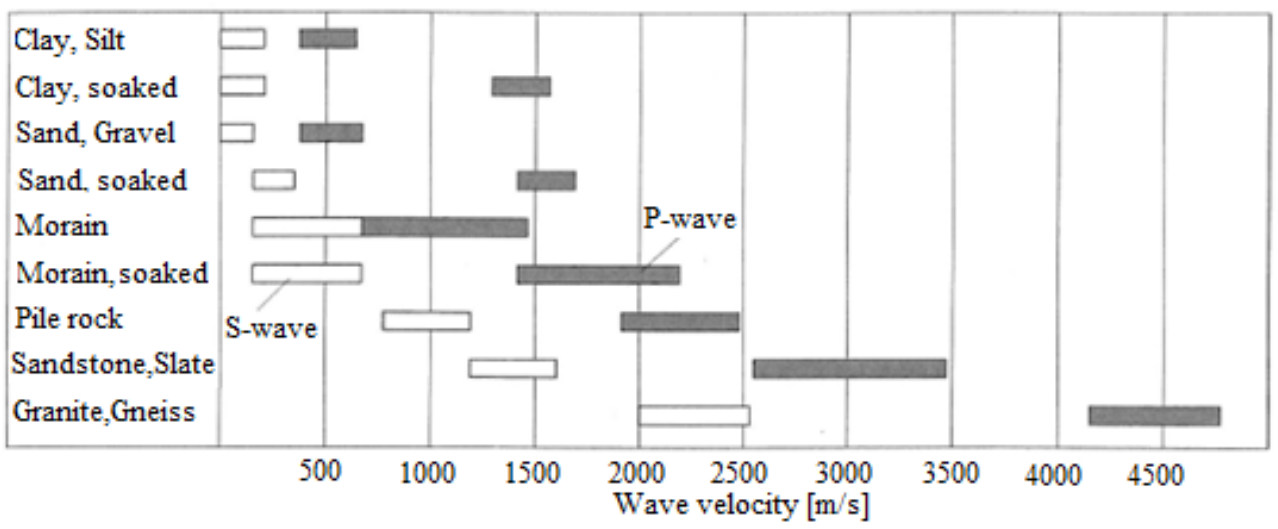

Fig. 3. Typical ranges of $P$ - and $S$-wave velocities for different subsoil conditions [13].

The consideration of SSI effects is very important. The influences of stiffness and damping characteristics of the soil on the structure are not negligible. There are many ways of mathematical representation of the soil. The soil can be represented by a set of equivalent springs or by continuum. For FE modelling, it is well known that a narrow domain with fixed boundaries is not likely to represent realistic soil behavior, whereas a 
very large domain would result in a too complicated problem. It is, therefore, necessary to find an optimum value that reflects the realistic behavior of soil without significant loss in accuracy. The spring stiffness of the soil under the concrete block foundation can be determined in accordance with the [14] as follows

$$
K_{\mathrm{v}}=\frac{4 G_{d} r_{\circ}}{1-v}, \quad K_{\mathrm{h}}=\frac{32(1-v) G_{d} r_{\circ}}{7-8 v}, \quad K_{\psi}=\frac{8 G_{d} r_{\circ}^{3}}{3(1-v)}, \quad K_{\ominus}=\frac{16 G_{d} r_{\circ}^{3}}{3}
$$

$r_{o}=\sqrt{W \frac{L}{\pi}}$ for translation, $r_{o}=\left(\sqrt{W \frac{L^{3}}{3 \cdot \pi}}\right)^{1 / 2}$ for rotation, $r_{o}=\left(\sqrt{W L \frac{W^{2}+L^{2}}{6 . \pi}}\right)^{1 / 2}$ for torsion, where $W$ is the width of foundation, $L$ - length of foundation.

\section{Calculation model}

The finite element software ANSYS [15] have been used for all models and analyses. The model of the bridge was for deterministic and consistently for probabilistic analysis prepared.
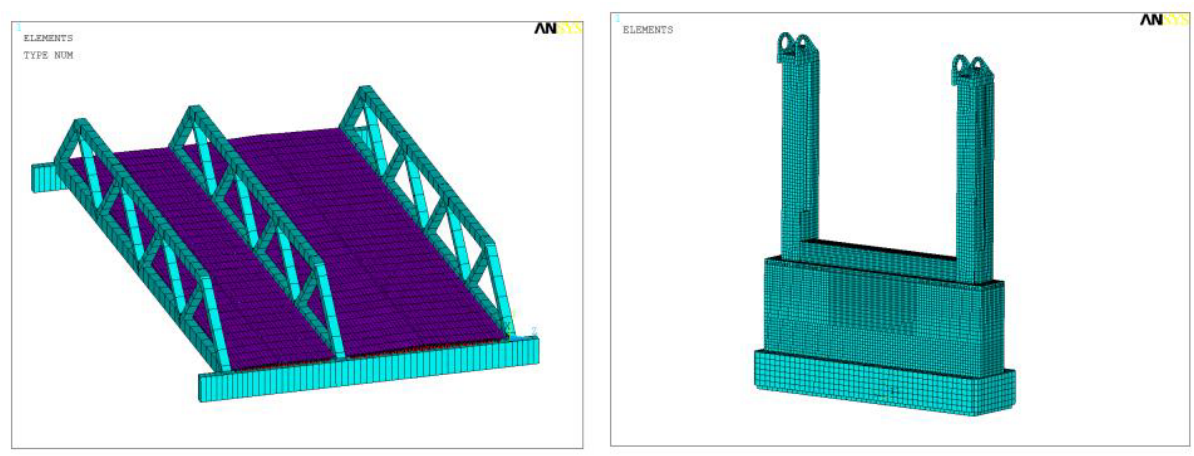

Fig. 4. FEM model of the bridge deck and pylon.

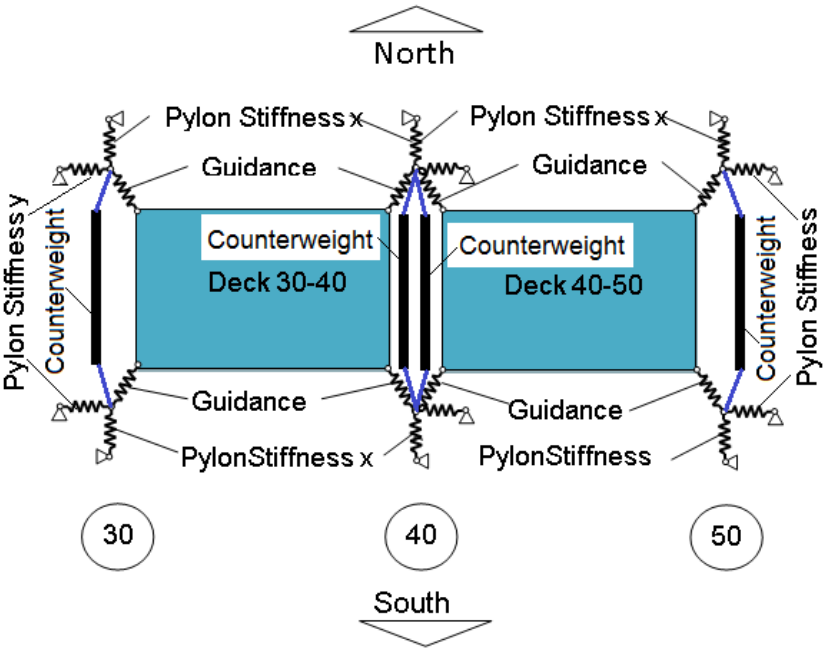

Fig. 5. Scheme of complete system in plan view: two decks, pylons and counterweights. 
The elements SOLID186, SOLID187 and SURFACE154 were used in this detailed FEM model. The preliminary analyses have shown, that the vertical displacements of the tops of the pylons are neglectable in comparison to the horizontal displacements. For that reason was the simplification of the model in $2 \mathrm{D}$ possible. The model consist of two approximately rigid plates (decks) with weight $G$ and substituted thickness $H$, models of pylons - springs with stiffness $K$. SHELL63 and LINK8 finite elements were applied.

Let consider situation when the both decks are in upper position. The mass more than 8000 tons is in the height of more than $30 \mathrm{~m}$ supported by six pylons. The system is sensitive to horizontal loading e.g. wind loading, seismic loading. The natural frequencies and modes of the bridge system influence the dynamic behavior of the bridge system. The dynamic component of the loading depends on the base of Eurocode $[16,17]$ and on natural frequency of the structure and can be calculated according to Eurocode procedure [18].

\section{Probability and sensitivity analysis}

The deterministic eigenvalue analysis tested the model used for the probabilistic analysis [5]. The uncertain parameters $K, G$ and $H$ were defined as random input variables (Table 2.) as follows:

$$
K=K_{\mathrm{d} .} \Phi\left(\boldsymbol{k}_{\text {var }}\right), G=G_{\mathrm{k} .} \Phi\left(\boldsymbol{g}_{\text {var }}\right), H=H_{\mathrm{k} .} \Phi\left(\boldsymbol{h}_{\text {var }}\right),
$$

where $K_{\mathrm{d}}, G_{\mathrm{k}}$ and $H_{\mathrm{k}}$ are the characteristic values of the input data, $\boldsymbol{k}_{\text {var }}, \boldsymbol{g}_{\text {var }}, \boldsymbol{h}_{\text {var }}$ are the variable parameters and $\Phi($.$) is the distribution function of the variables (Table 2).$

Special macro has been written in APDL ANSYS [15] using LHS simulation method to the probabilistic analysis of this calculation model. The uncertainties are coming from the standard requirements and the other publications [3, 5, 7, 18 and 19]. The mean values and standard deviations were defined in accordance of the experimental test and design values of the material properties and the action effects (see Table 2). Based on the results from the simulated modal analysis of the Boltek bridge and the variability of the input parameters $10^{4}$ LHS simulations were performed in the software ANSYS. The sensitivity analyses give us the informations about the influences of the variable properties of the input data to the output data (Fig. 6). These analyses are based on the correlations matrixes.

Table 2. Variability of input parameters [19].

\begin{tabular}{|l|c|c|c|c|c|c|c|}
\hline Quantity & $\begin{array}{c}\text { Charact. } \\
\text { value }\end{array}$ & Variable & $\begin{array}{c}\text { Histog. } \\
\text { type }\end{array}$ & $\begin{array}{c}\text { Mean } \\
\boldsymbol{\mu}\end{array}$ & $\begin{array}{c}\text { Deviat. } \\
\text { o\%o] }\end{array}$ & $\begin{array}{c}\text { Minim. } \\
\text { value }\end{array}$ & $\begin{array}{c}\text { Maxim. } \\
\text { value }\end{array}$ \\
\hline Stiffness & $K_{d}$ & $k_{\text {var }}$ & $\mathrm{N}$ & 1 & 20 & 0.451 & 1.490 \\
\hline Plate thickness & $H_{k}$ & $h_{\text {var }}$ & $\mathrm{N}$ & 1 & 5 & 0.808 & 1.195 \\
\hline Dead load & $G_{k}$ & $g_{\text {var }}$ & $\mathrm{N}$ & 1 & 5 & 0.808 & 1.195 \\
\hline Action & $E_{k}$ & $e_{v a r}$ & $\mathrm{~N}$ & 1 & 5 & 0.813 & 1.190 \\
\hline Resistance & $R_{k}$ & $r_{v a r}$ & $\mathrm{~N}$ & 1 & 5 & 0.812 & 1.201 \\
\hline
\end{tabular}

We used four models considering the various numbers of the input data (see Table 3 ). The uncertainties of the pylon stiffness considering the soil-stiffness interaction to the modal characteristic of the Boltek Bridge were investigated. In the case of the model 1 two 
independed characteristics were considered. In addition 18 independed input characteristics were considered in the model 4 (see Table 3 ). The extrem values of the interval of the mode distribution functions are in the model 2 with 3 independed input characteristics (pylon stiffnes $K$, masses $G$ and model uncertainties action $E$ ). The interval of the response distribution function diminishes with the increase number of the input variables.

Table 3. Analysis of the influence of the input data uncertainties to the Bridge frequencies.

\begin{tabular}{|c|c|c|c|c|c|c|c|c|c|c|}
\hline \multicolumn{2}{|c|}{ Number of } & \multicolumn{3}{|c|}{ First mode } & \multicolumn{3}{c|}{ Second mode } & \multicolumn{3}{c|}{ Third mode } \\
\hline Model & $\begin{array}{c}\text { Variab. } \\
\text { data }\end{array}$ & Min & Mean & Max & Min & Mean & Max & Min & Mean & Max \\
\hline 1 & 2 & 0.809 & 1.202 & 1.676 & 0.964 & 1.432 & 1.996 & 1.353 & 2.010 & 2.802 \\
\hline 2 & 3 & 0.738 & 1.202 & 1.711 & 0.880 & 1.432 & 2.038 & 1.235 & 2.010 & 2.861 \\
\hline 3 & 14 & 0.993 & 1.108 & 1.227 & 1.287 & 1.428 & 1.589 & 1.612 & 1.850 & 2.101 \\
\hline 4 & 18 & 0.898 & 1.111 & 1.367 & 1.155 & 1.429 & 1.718 & 1.613 & 2.016 & 2.594 \\
\hline
\end{tabular}
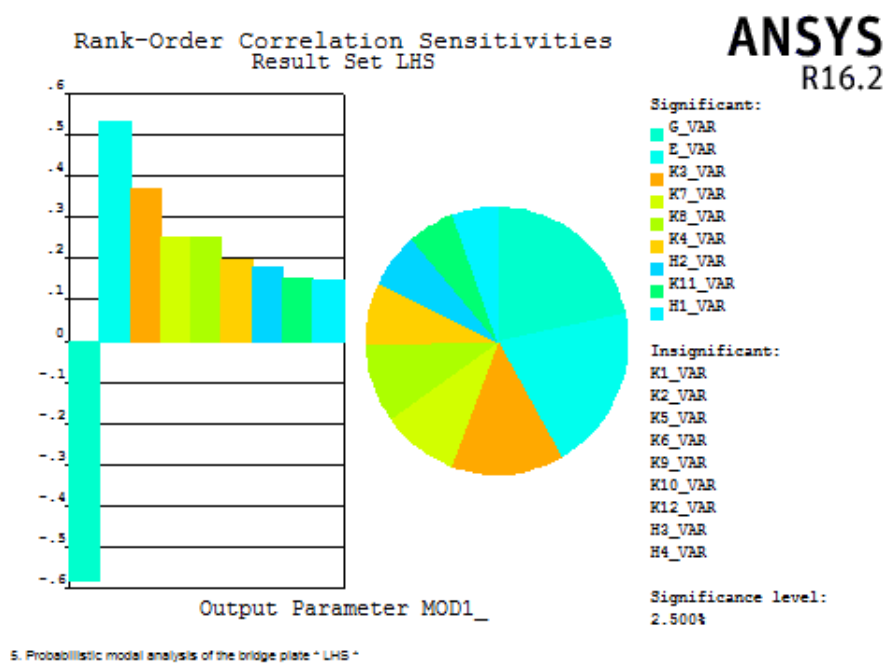

Fig. 6. Sensitivity analysis of the influences of the number of the variable input data to the first modeModel 4 with 18 variable parameters .

\section{Conclusion}

The paper presents the probability and sensitivity analysis results of the movable bridge. For the design of the new Botlek Bridge soil deformations can potentially have a major effect on one of the most critical design requirements, which is a limited rotation of the large foundation footing. Application of a simplified stochastic subsoil model enabled a quantitative risk analysis in order to deal with the uncertainties described in this paper. The decks were considered in top position. The stiffness of the pylons and weight of decks were 
as random input variables defined. The first, second and the third natural frequencies were as output parameters defined. The results were useful in dynamic analysis of wind impact.

The project was performed with the financial support of the Grant Agency of the Slovak Republic (VEGA 1/0265/16).

\section{References}

1. C. Bucher, Computational Analysis of Randomness in Structural Mechanics (Taylor \& Francis Group, London, UK, 2012)

2. A. Haldar and S. Mahadevan, Probability, Reliability and Statistical Methods in Eng. Des. (J.W. \& S., New York, 2000)

3. Holický M. et al. Basics for Assessment of Existing Structures, Base of Reliability Theory and Risk Evaluation (Ed. K.I. CTU Prague, 2013)

4. Z. Kala, Applications of Global Sensitivity Analysis Methods in Civil Engineering, In Proc. ESREL 2015, Zürich (Switzerland), pp. 2541-2545 (2015)

5. J. Králik, Reliability Analysis of Structures Using Stochastic Finite Element Method, (Pub. by STU Bratislava, 143pp, 2009)

6. J. Králik, J. Králik, jr. Deterministic and Probabilistic Analysis of NPP Communication Bridge Resistance due to Extreme Loads, Trans. V̌́B TU Ostrava, 14, 54-63, DE GRUYTER OPEN (2014)

7. M. Krejsa, J. Králik, Probabilistic Computational Methods in Structural Failure Analysis, Jour. of Mult. Model. 6, 2, Imperial College Press (2015)

8. V. Salajka, J. Kala, Z. Čada, Modification of response spectra by probabilistic approach. ESREL 2014 (2015)

9. J. Melcer, Dynamic analysis of the new bridge across the Danube in Bratislava. Proc. of the 4th Int. Conf. on Bridges acr. the Danube 2001, Bratislava, 193-198 (2001)

10. R. E. Melchers, Structural Reliability: Analysis and Prediction (J.W\&S., Chichester, U.K. 1999)

11. Dynamic Analysis, Nieuwe Beweegbare Botlekbrug, Tech. Rep., VCE Consult ZTGmbH, pp. 1-219, August (2012)

12. J. A. Jacobse et al. Probabilistic Settlement Analysis for the Botlek Lifting Bridge Design, Proc. of the 18th Int. Conf. on Soil Mech. and Geot. Eng. Paris (2013)

13. H. Bachman et al., Vibration Problems in Structures. Practical Guidelines (Birkhäuser Verlag Basel, Berlin, 1995)

14. G. B. Baecher, and T. S. Ingra, Stochastic FEM in Settlement Prediction, J. of the Geot. Eng. Div. ASCE, 107, GT4, 451-463 (1981)

15. K. G. Bhatia, Foundation for Industrial Machines, Handbook for Practical Engineers, (D-CAD Publisher, New Delhi, 2009)

16. P. Kohnke, ANSYS, Theory, SAS IP Inc. Canonsburg (2008)

17. Eurocode 1990, Eurocode - Basis of structural design (CEN/TC250 Bruxelles 2002)

18. HANBOOK 5, Implem. of Euroc. Reliab. Back. Design of Buildings for the Fire Situation. L. Da V. P. Project CZ/02/B/F/PP-134007. Prague (2005)

19. JCSS 2011. JCSS Probabilistic Model Code. Zurich: Joint Committee on Structural Safety. www.jcss.byg.dtu.dk (2011) 